\title{
ASA 20IR SHOCK FEATURES IN MINERAL GRAINS FROM PSEUDOTACHYLITE BRECCIA OF THE MUSGRAVE PROVINCE AUSTRALIA
}

ABSTRACT
Early researchers interpreted the pseudotachylite
breccia from the Musgrave Province Australia
as generated by normal seismic processes
despite the large volume of the deposits. The
Musgrave pseudotachylite breccias deposits are
about $5 \mathrm{~km}$ wide and run intermittently for
300km with approximately $4 \%$ to $10 \%$
pseudotachylite melt. The seismic origin was
postulated based on the proximity of the
Woodroffe Thrust Fault, with up to three
generations of pseudotachylite melts found in
some of the Musgrave samples. This traditional
seismic interpretation continued even though
some pseudotachylite deposits are radial to an
impact center (MAPCIS) and $40 \mathrm{~km}$ from the
Woodroofe Thrust Fault along with multiple
generation pseudotachylite being known to
occur at other large impact sites.
The evidence on the mega and macro scale
along elemental analysis with having been
found and presented over the last ten years in
support of a large impact in central Australia
coeval with the established dating of the
Precambrian/Cambrian boundary, the ultimate
evidence is the finding of shock features within
the minerals, specifically the pseudotachylite
breccia, near the impact center.
Petrographic investigation revealed shocked
quartz grain with multiple sets of PDFs, along
with shocked feldspar and diaplectic glasses the
wall rock adjacent to the pseudotachylite melt.
The results strongly suggest Musgrave province
pseudotachylite breccia received shock forces
consistent with a large impact.

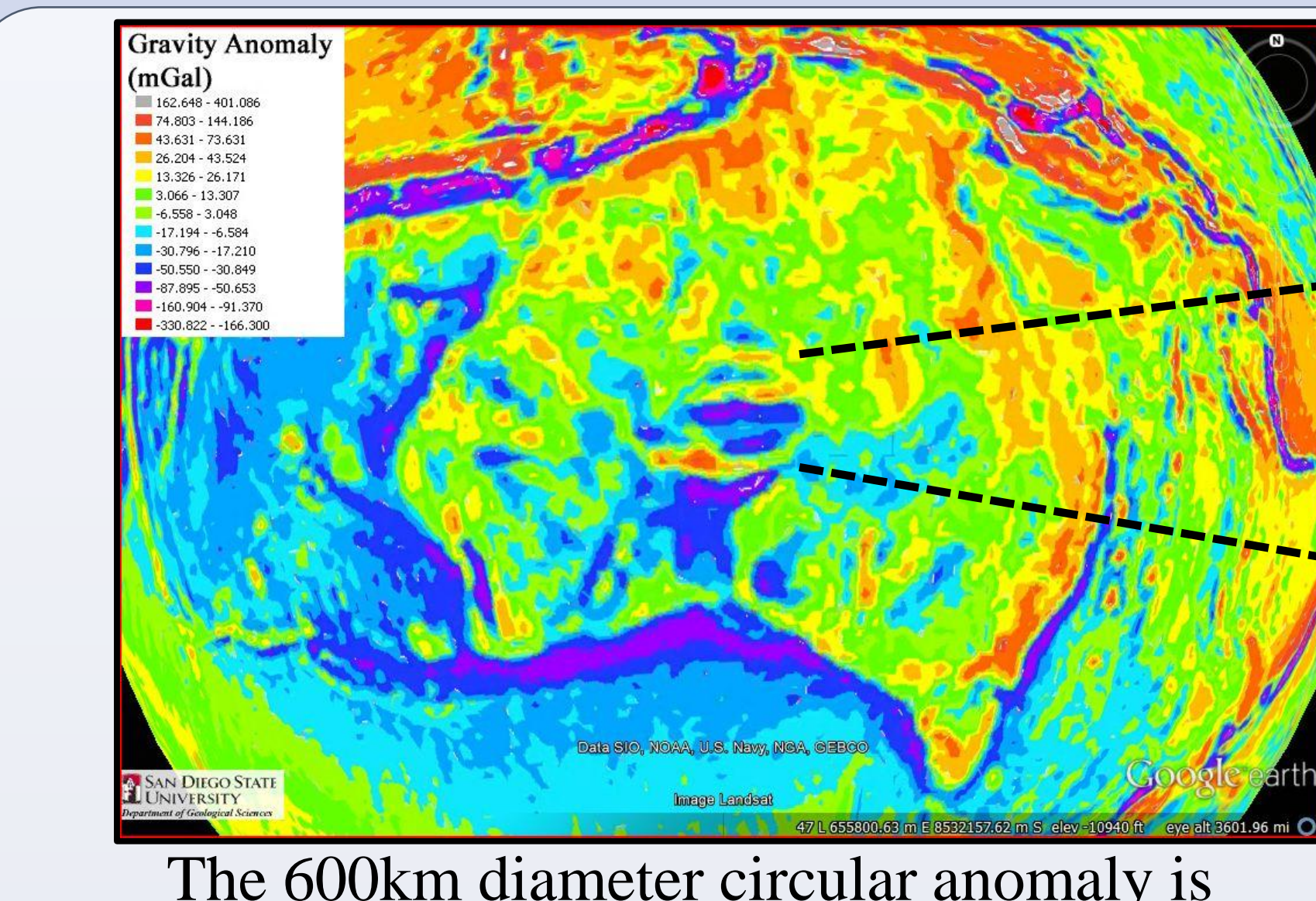

The 600km diameter circular anomaly is
clearly seen on the Grace Gravity Anomaly

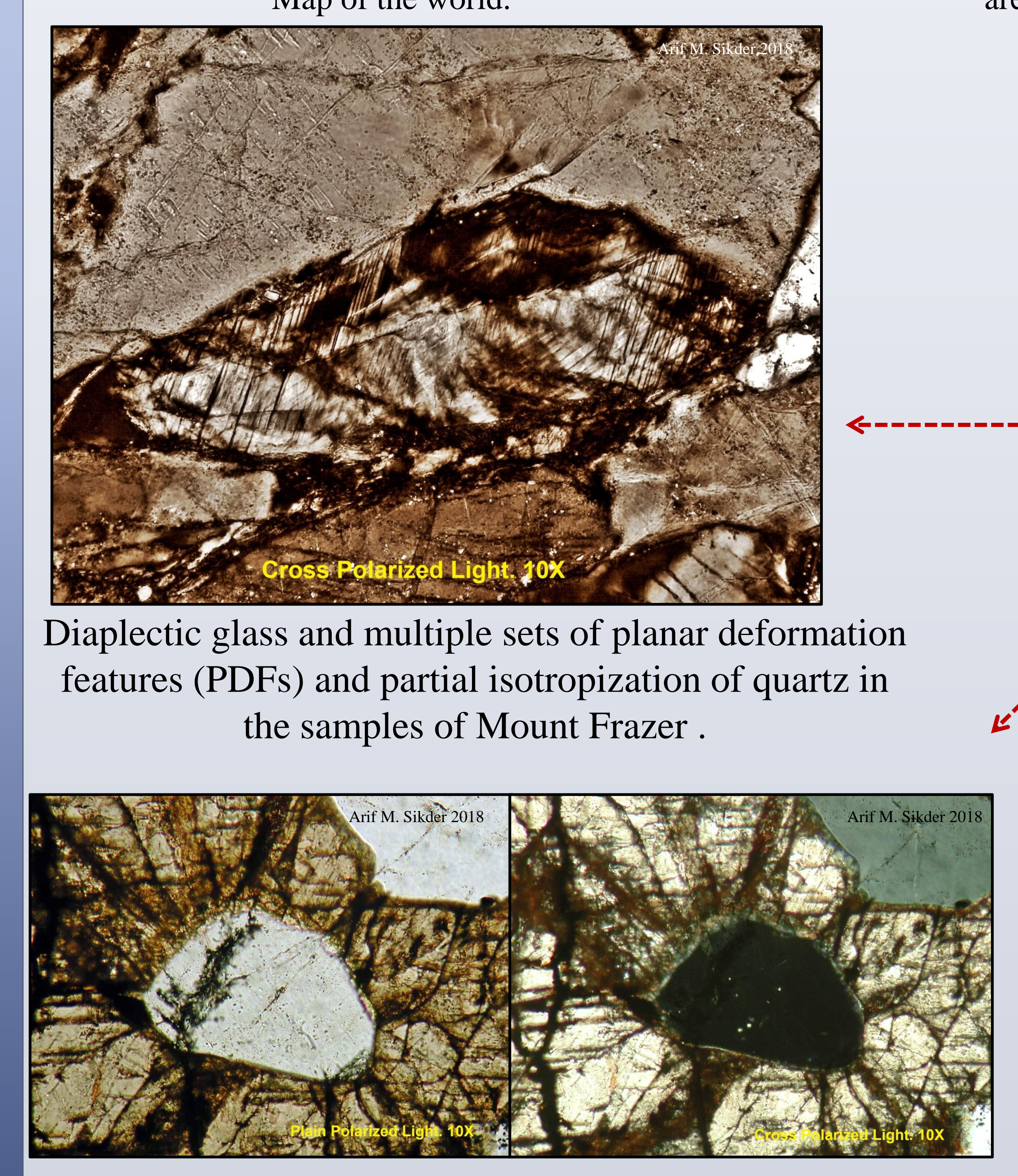

Thetomorph is diaplectic glass that usually retain their original shape, at even higher pressures, crystals may undergo atomic-structural displacements that convert them to glasses without passing through a melt stage.
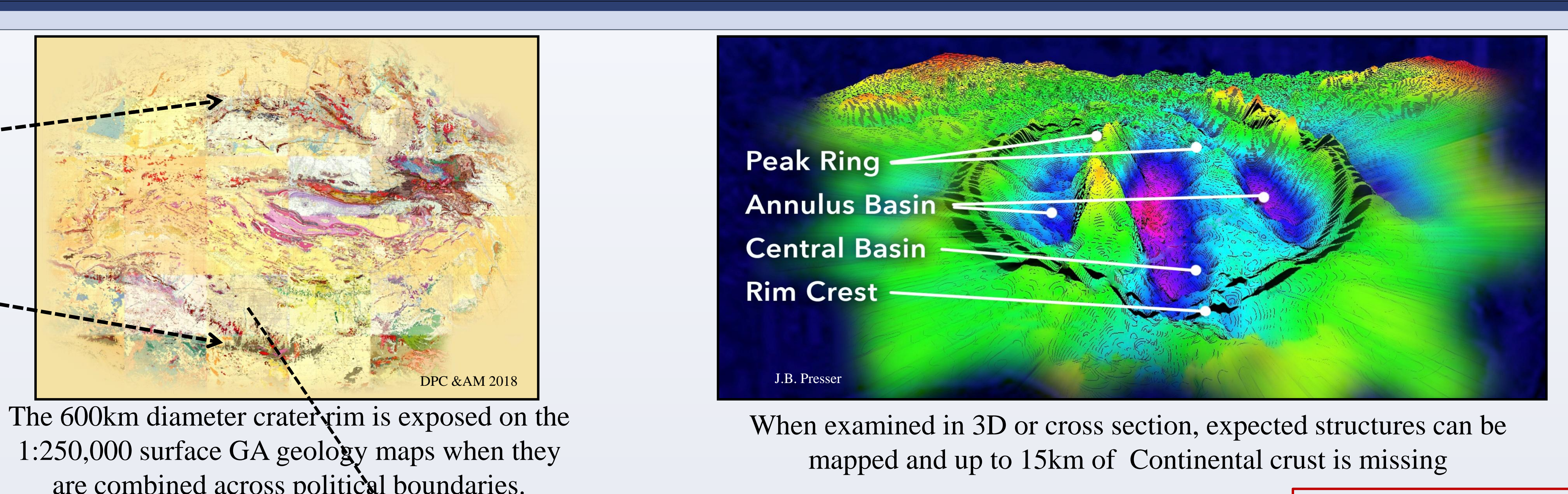

When examined in 3D or cross section, expected structures can be
mapped and up to $15 \mathrm{~km}$ of Continental crust is missing

combined across politicicl boundaries.
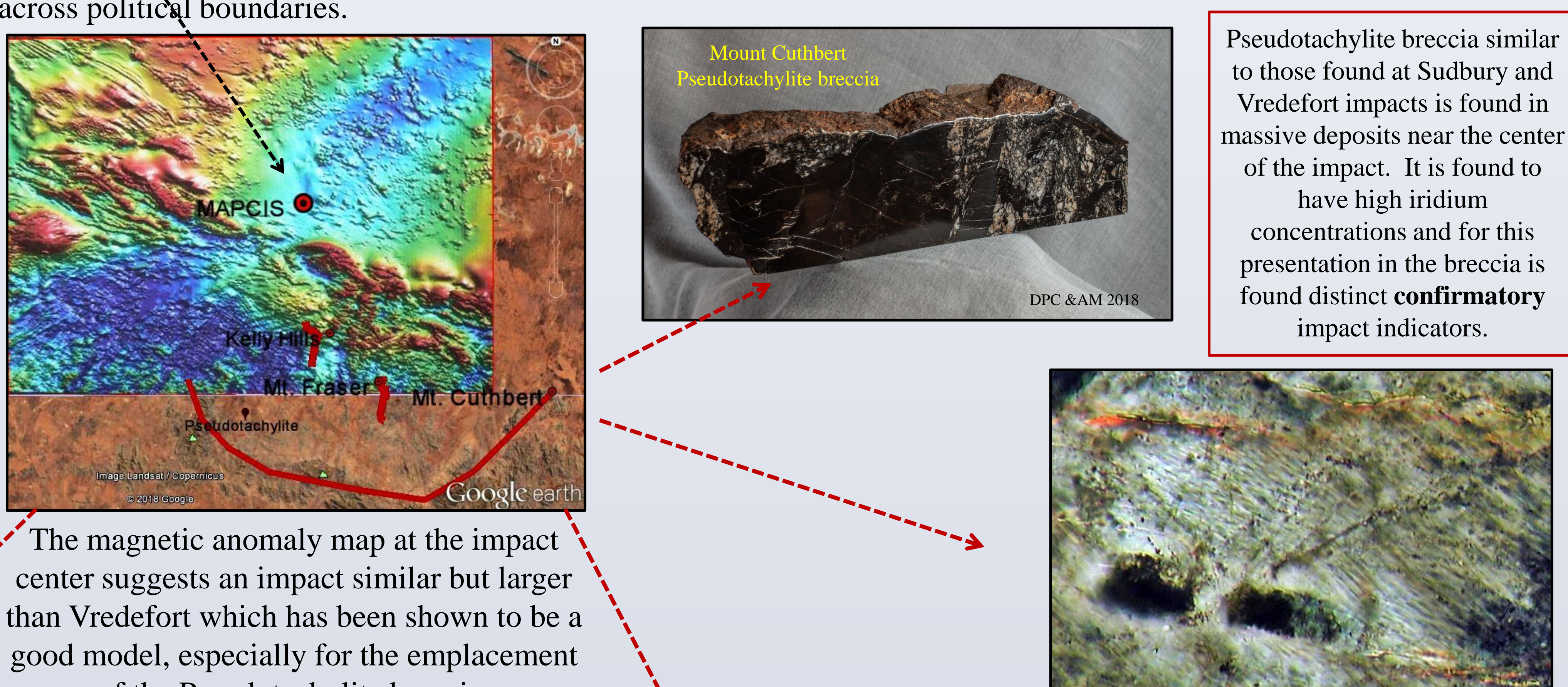

good model, especially for the emplacemen

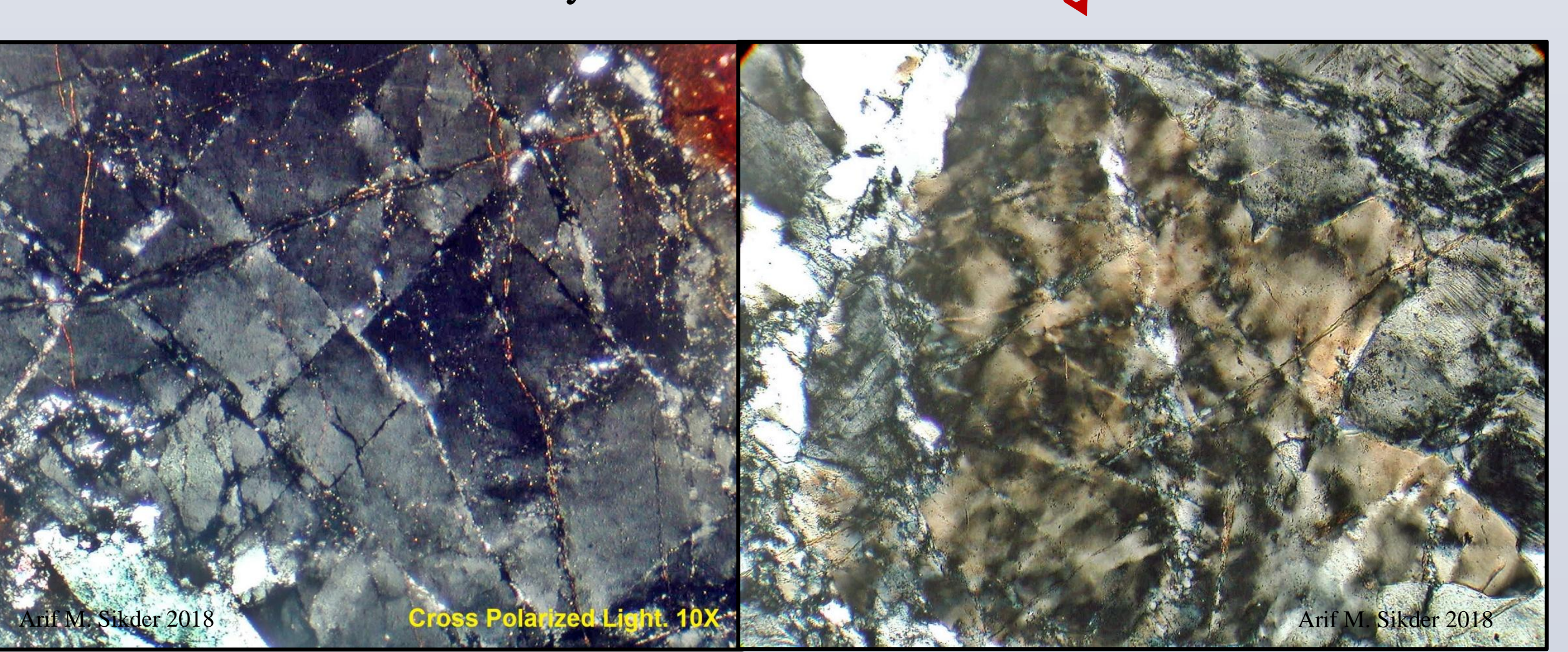

Effects of Shock metamorphism in quartz grains resulted in the

development of intersection of two sets of micro fractures with development of intersection of two sets of micro fractures with
displacement and spots of partial isotropization, i.e. diaplectic glass

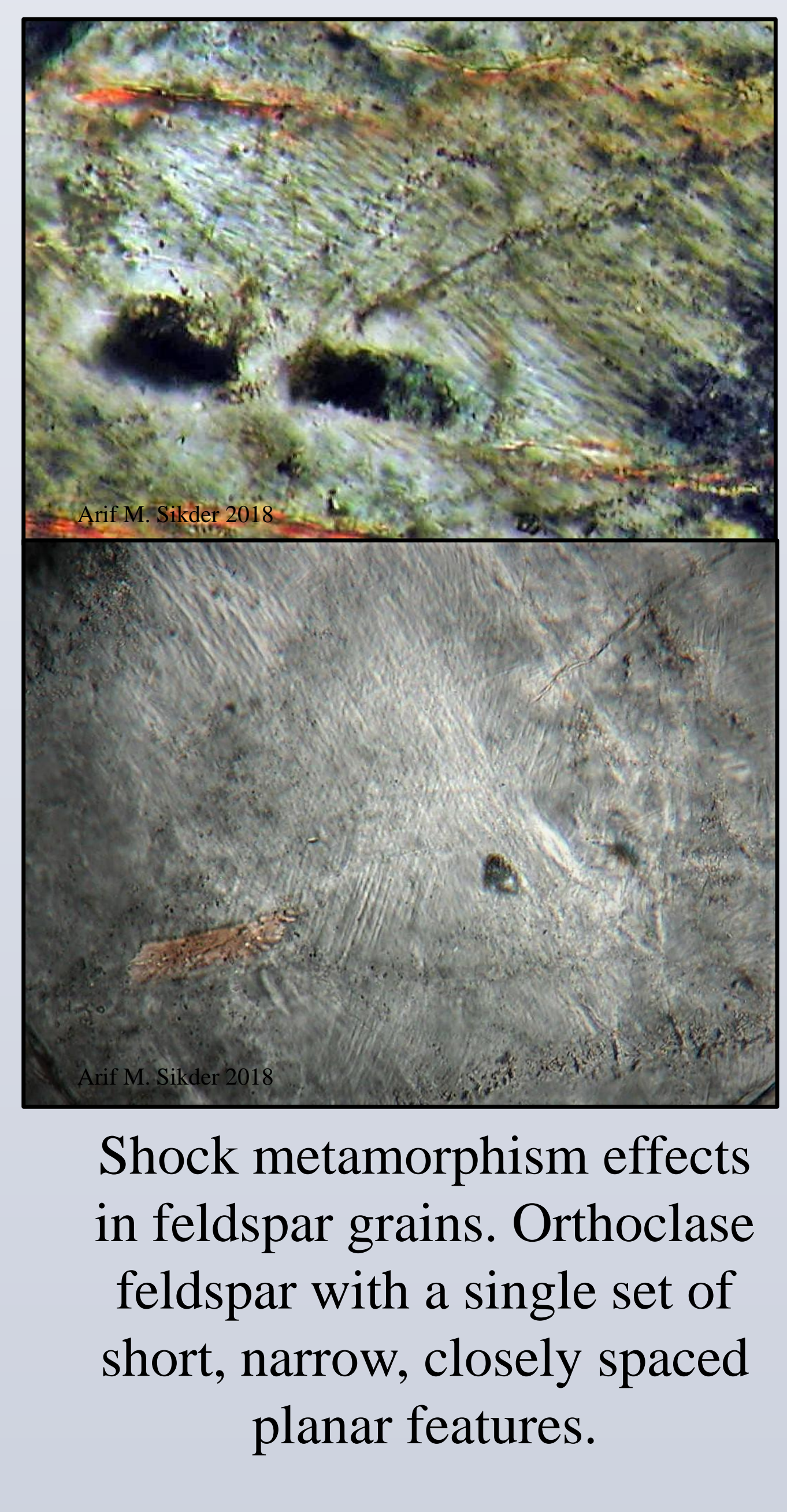

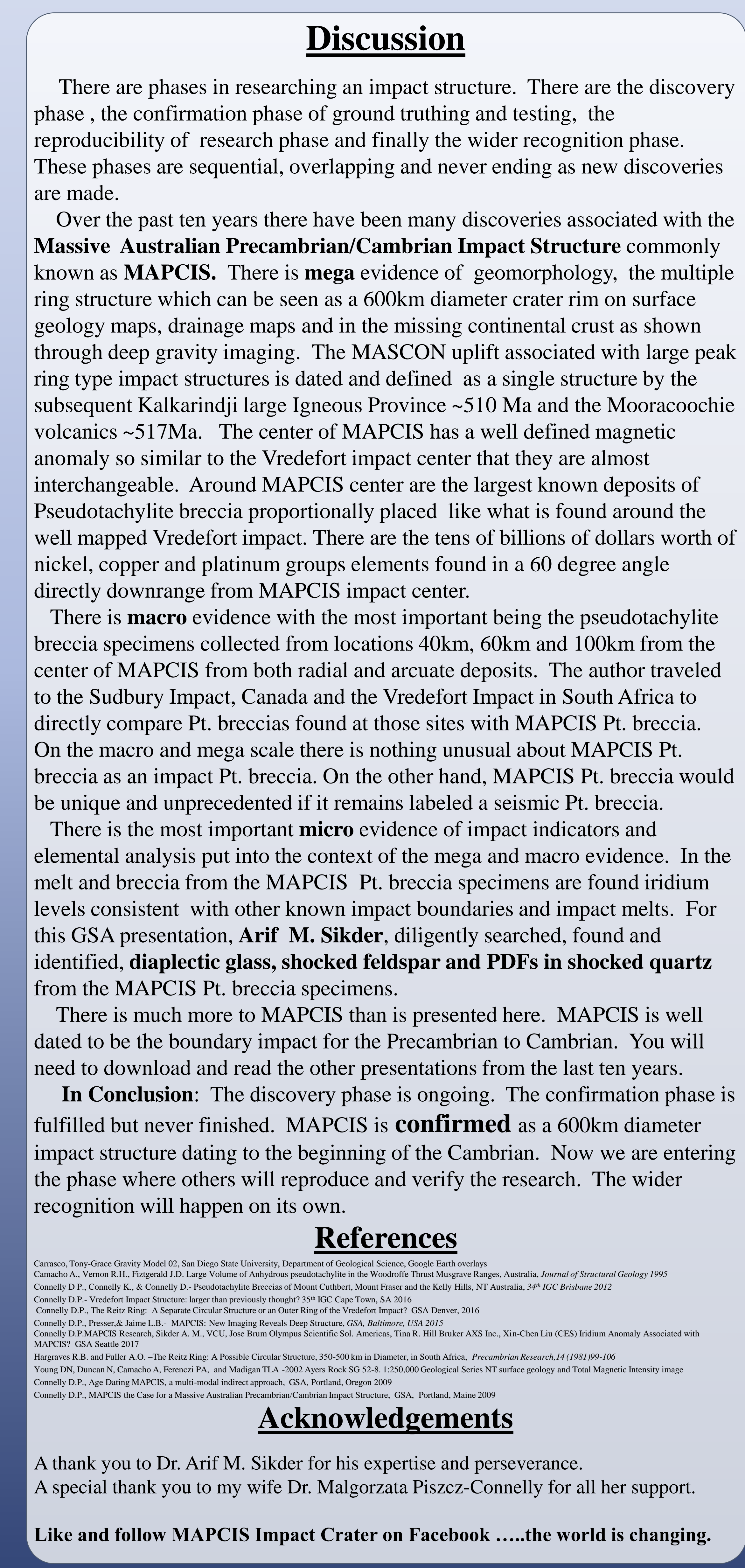

